\title{
Bithynialı İki Yazar: \\ Lucius Flavius Arrianus ve Cassius Dio Cocceianus
}

\author{
Hülya BOYANA ${ }^{1}$ - Ahmet TÜRKAN ${ }^{2}$
}

\begin{abstract}
$\ddot{O} \mathbf{z}$
Bithynia'nın farklı iki kentinde doğmuş olan Lucius Flavius Arrianus (yak.MS 86-160) ve Cassius Dio Cocceianus (yak.MS 155-235) İmparatorluk Roma'sının iki önemli devlet adamı ve yazarıdır. İkisi de Roma ile yakın ilişki içinde bulunmuş, hatta Arrianus kendi dönemi içinde bakıldığında Asia'dan çıkan sayılı senatör ve consülden biri olmuştur. Cassius Dio ise ondan bir kuşak sonra hem politika hem de yazarlık sahnesinde kendini göstermiş ve başarılı olmuştur. $\mathrm{Bu}$ iki karakter başta tarih olmak üzere coğrafya, strateji, biyografi gibi pek çok alanda eser kaleme alarak geçmişin ve kendi dönemlerinin izlerini muhafaza etmişler ve hem tarih yazıcılığında hem de politik yaşantıda etkili olmuşlardır. Çalışma, bu iki yazar ve siyasetçinin hayatı ve eserleri hakkında bir derleme sunmayı amaçlamaktadır.
\end{abstract}

Anahtar Kelimeler: Lucius Flavius Arrianus, Cassius Dio Cocceianus, Roma, Cursus Honorum, Tarihyazıcılığı, Askeri Tarih

Two Bithynian Writers:

\section{Lucius Flavius Arrianus and Cassius Dio Coccecianus}

\begin{abstract}
Lucius Flavius Arrianus (c. 86-160 AD) and Cassius Dio Cocceianus (ca. 155$235 \mathrm{AD}$ ) who were born in two important cities of the Bithynia were two important writers and statesmen of Roman Imperial period. Both had close relations with Rome, and Arrianus was one of the few senators and consuls from Asia in his own time. Cassius Dio, on the other hand, became successful in both politics and writing a generation later. These two characters have preserved the traces of the past and their own periods by writing in many fields such as geography, strategy, and biography, especially history, and have been influential in both historiography and political life. The study aims to present a compilation about the life and works of these two writers and politicians.
\end{abstract}

Keywords: Lucius Flavius Arrianus, Cassius Dio Cocceianus, Rome, Cursus Honorum, Historiography, Military History

\footnotetext{
${ }^{1}$ Prof. Dr., Ankara Üniversitesi, Dil ve Tarih, Coğrafya Fakültesi, Tarih Bölümü, Eskiçağ Tarihi Anabilim Dal1, e-posta: boyanahulya@gmail.com. https://orcid.org/0000-0003-3786-8244

${ }^{2}$ Dr.Arş.Gör., Eskişehir Osmangazi Üniversitesi, Fen - Edebiyat Fakültesi, Tarih Bölümü, Eskiçağ Tarihi Anabilim Dalı, e-posta: aturkan@ogu.edu.tr. https://orcid.org/ 0000-0002-3358-0828
} 
Kuzeyde Karadeniz (Pontus Euxieinos), batısında Çanakkale Boğazı (Hellespontos), İstanbul Boğazı (Bosphoros) ve Karaçay (Rhyndakos), güneyinde Sakarya Irmağı (Sangarios), doğusunda ise Filyos Çayı (Billaios) ile sınırlanan, Asya ve Avrupa arasında geçiş yollarının kavşağında yer alan Bithynia bölgesinde doğmuş olan Lucius Flavius Arrianus (yak.MS 86-160) ve Cassius Dio Cocceianus'un (yak.MS 155-235), İmparatorluk Roma'sının iki önemli yazarı ve devlet adamıdır. İkisi de cursus honorum'unu tamamlayıp senatör ve consül olmuştur ve Hellen dünyasından çıkıp imparatorluk üzerinde önemli etkilerde bulunmuştur. $\mathrm{Bu}$ çalışmada, bu iki yazarın hayatı ve eserleri hakkında bir panorama sunarak Eskiçağ tarihi yazımı ve kaynaklarına bir katkı sunmak amaçlanmıştır.

\section{Arrianus'un Yaşamı}

Arrianus'un yaşamı ile ilgili bilgileri, yazarın kendi eserlerinden ve ayrıca Lucianos $^{3}$, Cassius Dio Cocceianus, Photios ${ }^{4}$ ve Suidas'ın ${ }^{5}$ yazdıklarından öğrenmekteyiz. Bununla birlikte yazıtlar da yazarın hayatıyla ilgili önemli bir veri kaynağıdır. Hatta Arrianus'un fiziksel görünümü hakkındaki bilgilerimizi de bu kaynak grubuna borçluyuz. ${ }^{6}$

Bithynia Eyaleti'nin başkenti Nikomedeia'da (bugünkü İzmit) doğan Lucius Flavius Arrianus Neos Ksenophon, yaklaşık MS 85-180 yılları arasında yaşamıştır. ${ }^{7}$ Lucius praenomen'i (ön adı), Flavius nomen'i (soy-kabile ad1), Arrianus ise cognomen'i'dir. Bir tarihçi ve filozof olan Arrianus, "yeni" ya da "ikinci Ksenophon" olarak tanımlanmaktadır. Bu, isminin bir bölümü değil, tarihçinin unvanıdır. ${ }^{8}$ Doğum tarihi kesin olarak bilinmemektedir. Ancak yazarın Roma'da

\footnotetext{
${ }^{3}$ Lucianos, MS 115-180 yılları arasında yaşayan sofist, hatip ve hiciv yazarıdır. Arrianus ile çağdaş olan yazar, eserlerini Arrianus gibi Hellen dilinde yazmıştır.

${ }^{4}$ Photios, MS 810-893 yılları arasında yaşayan Byzantion patriği.

${ }^{5}$ Suda, MS 10. yüzyılda Hellen tarihi ve edebiyatı üzerine değerli yazılar içeren sözlük ve ansiklopedi, kişi adı gibi Suidas şeklinde de kullanılmıştır.

${ }^{6}$ G. W. Bowersock, "A New Inscription of Arrian" Greek, Roman, and Byzantine Studies 8 (1967), $279-80$.

${ }^{7}$ FGrH II B 156 T 1-4.

${ }^{8}$ Walter Ameling, “L. Flavius Arrianus Neos Xenophon”, Epigraphica Anatolica 4, Bonn 1984, 122.
} 
consul'lük yaptı̆̆g MS 129 yılından hareketle, doğum tarihini en erken 85, en geç 92 yılı olduğunu söylemek mümkündür. ${ }^{9}$

Flavius nomen'i babasının Flavius Hanedanı döneminde yurttaşlık elde ettiğine dair yorumların yapılmasına neden olmuştur. Bir Roma yurttaşı olarak doğmas1 ve daha sonra senatörlük görevine kadar yükselmesi, Roma'nın eyaletlerden gelen senatörleri, o bölgelerin önde gelen ve bölgede çeşitli makamlarda bulunmuş ailelerinden seçme anlayışı düşünüldüğünde, Arrianus'un da aristokrat bir aileden olduğun söylenebilir. ${ }^{10}$ Çocukluk ve ilk gençlik yıllarını Nikomedeia'da geçirmiştir. Bu süreçte avcılık ve savaş stratejileri üzerine eğitim almıştır. ${ }^{11}$ Erken yaşta Latince öğrenmek, söz konusu dönemde çeşitli makamlar üstünde iddiaları olan aileler için önemli bir standart oluşturduğunu göz önünde bulundurulursa, Arrianus'un da Nikomedia'da henüz çocukken Latince öğrendiği söylenebilir. Cappadocia valiliği sırasında Hadrianus'a yazdığı mektuplar da bu dili iyi kullandığını göstermiştir ${ }^{12}$ Kendisi için bir devlet kariyerinin tasarlanmış olması, henüz bu erken yaşlarda Nikomedeia'daki Demeter Kültür rahipliği yapmasından da anlaşılmaktadır. ${ }^{13} \mathrm{Bu}$, Arrianus'un cursus honorum'unun başlangıcıdır. ${ }^{14}$

Arrianus 19 yaşında Nikomedeia'dan ayrılarak söz konusu dönemin pek çok aristokrat Hellen genci gibi bir sofist ya da filozoftan eğitim almak için memleketinden ayrılmıştır. Hellas'ın kuzeybatısında bulunan Epirus bölgesinin kentlerinden Nikopolis'e (Niğbolu) gitmiştir. Burada Stoacı filozof Epiktetos'un

\footnotetext{
${ }^{9}$ Stadter, Philip. A., Arrian of Nicomedia, The University of North Carolina Press, Chapel Hill 1980., 3.

${ }^{10}$ Michael Woloch, Raoman Citizenship and the Athenian Elite, A.D.96 -161, Amsterdam 1973, 219; Stadter, 2; Murat Arslan, Arriani Periplus Ponti Euxini $=$ Arrianus 'un Karadeniz Seyahati. Çev.ve Yor.: M. Arslan, İstanbul 2005, VII.

${ }^{11}$ Ronald Syme., "The Career of Arrian”, HSCP 86, Harward (1982): 181; Arrianus'un çocukluğu hakkında aktardığ tek şey budur, bkz. Bith. Fr.1.1.

${ }^{12}$ Wverett Lynn Wheeler, Flavius Arrianus: A Political and Military Biography, Doktora Tezi, Duke University Department of Classsical Studies, Durham, (1970): 18-19.

${ }^{13}$ Bazı araştırmacılar bu rahipliğin Cappadocia valiliğinden sonra olduğunu düşünmektedir. Buna karşılık Arrianus'un bu dönemdeki mevkii ve itibarı göz önünde bulundurulduğunda rahipliğin bu yazarın bu dönemine pek uygun düşmediğini öne sürmüştür. Onlara göre Arrianus Demeter rahipliğinde genç yaşlarda bulunmuştur. E.L. Bowie, Greek and their Past in the Second Sophistic", P\&P 46, (1970): 3 vd. Bizim düşüncemiz de Arrianus'un Demeter rahipliğini Nikomedia'dan ayrılmadan önce yapmıș olduğu yönündedir.

${ }^{14}$ FgrHist II B 156 T 4 "Arrianos" = Phot. Bib. 93. 73a 35; Albert B. Bosworth, "Arrian's Literary Development", Classical Quarterly 22 (1972): 184; Sarıkaya, 330.
} 
okulunda eğitim almıştır. ${ }^{15}$ Arrianus'un, Epiktetos’tan ders almak için Nikopolis’te ne kadar süre kaldığını söylemek imkansızdır fakat uzun bir süre Epiktetos'un en sadık öğrencileri arasında olduğu bilinmektedir. Arrianus'un, daha sonra Roma İmparatoru olacak Hadrianus (MS 117- 138) ile burada tanışmış olması ihtimaller arasındadır. ${ }^{16}$ Onların yakın dostlukları burada başlamış olabilir. Hatta Arrianus ile Hadrianus, felsefe derslerini birlikte de almış olabilir. ${ }^{17}$

Delphoi'da tespit edilen yazıtlarda, Hadrianus'un yakın dostu olan, MS 111 114 yılları arasındaki Akhaia valiliği yapmış olan (legatus Augusti pro praetore) C. Avidius Nigrinus'un danışmanlığını (consilium) yaptığını göstermektedir ${ }^{18}$ Avidius Nigrinus'un Hadrianus'un yakın arkadaşı olduğunu ${ }^{19}$ ve bu süreçte, MS 112 yılında Atina'da arkhon olan Hadrianus ile Arrianus arasındaki dostluğun ilerlediği düşünülebilir. ${ }^{20}$ Bunun yanında, söz konusu dönemde önemli bir entelekjtüel figür hâline gelen Plutarkhos ile tanışması da olasıdır. Nigrinus, iki Apollon rahibinden bişri olan Plutarkhos'u şahsen tanımıştır ${ }^{21}$ fakat Arrianus ile Plutarkhos'un bizzat tanıştığına dair herhangi bir kanıt bulunmamaktadır.

Arrianus MS 113 - 114 yıllarında Epiktetos'un yanından ayrılmış olmalıdır. MS 116 - 117 yıllarında Traianus'un Parth seferine katılmış olması olasıdır. Bu seferin sona ermesinin ardından Roma'ya gitmiş ve Hadrianus'un imparatorluğunun ilk zamanlarınbda quaestor'luk yapmıştır ve MS 121 yılında preator unvanını almıştır ki bu da onun en geç bu tarihlerde senatus'a kabul edildiğini göstermektedir. Araştırmacılar Arrianus'un senatus'a kabul edildiği yaşın daha erkene, onun 25 yaşına kadar geri gittiğini öne sürmektedir. MS 129 - 130 yıllarında konsüllük yapmıştır. ${ }^{22}$ Preator'luğundan consul'lüğe geçen bu on y1lda Arrianus'un

\footnotetext{
${ }^{15}$ Eduard Schwartz, "Arrianus", $R E$ III, Stuttgart 1895, 1230. Epiktetos yak. MS 50-120 y1llar1 arasında yaşayan Phrygia Hierapolis (Pamukkale) kenti stoacı filozoftur. Arrianus, Epiktetos'un yanına MS 108 yılında gitmiştir. bk. Fergus Millar., "Epictetus and Imperial Court", JRS LV, London 1965, 141. Stadter, Arrian of Nicomedia, 5'te ise Arrianus'un Nikopolis'e 18 yaşında gittiğini, bu tarihin de MS 107'e denk geldiğini söylemektedir. Bununla birlitke

${ }^{16}$ Hist. Aug. Vit. Hadr. XVI, 10.

${ }^{17}$ Syme, 190.

${ }^{18}$ CIL III.585, 12306.

${ }^{19}$ Arslan, VIII-IX; Sevgi Sarıkaya “Arrianus'un İskender'den Sonraki Olaylar” Adlı Eseri”, Cedrus I (2013): 330 .

${ }^{20}$ Arslan, IX.

${ }^{21}$ Wheeler, 27.

${ }^{22}$ CIL XV 244; Syme, 183.
} 
cursus'unu nasıl tamamladığı konusunda parçalı ve az sayıda kanıtı izlemek gerekmektedir.

Hadrianus, O'nu MS 121'de Gallia, Germania ve Britania'ya seferlere götürmüştür. ${ }^{23}$ Böylece iki önemli tarihi kişi arasında yakın bir dostluk başlamıştır. $\mathrm{Bu}$ dostlukta Arrianus'un bilgi birikimi ve uygulama yeteneğinin olması, Hadrianus'un gözünde O'nun değerini yükselttiğini görmekteyiz. Aynı zamanda imparator Hadrianus, Roma İmparatorluğu'nda farklı ırkların Roma vatandaşlığı kavramı altında bir arada yaşamalarını istiyordu. Bu amaçla İmparator, Hellen kültürü ile yetişmiş ve Roma vatandaşı olan, iyi eğitimli Arrianus gibi üniter bir imparatorluğun ideal bir vatandaşı olan, üst mevkilere gelen kişileri teşvik etmeyi doğal olarak hoş görmektedir. ${ }^{24}$ Bununla birlikte, Arrianus'un cursus'unun içinde lejyon komutanlığı da (legatus legionis) olabilir. Bir novus homo ${ }^{25}$ çoğu zaman consül'lük makamına ulaşmadan önce komutanlık görevi yapmış olurdu. Bu noktada Hadrianus ile olan seferleri de mantıklı hâle gelmektedir. Böylece yazarın Danube'de lejyon komutanlığı yaptığını söyleyebiliriz. ${ }^{26}$

Preator'luk ve Danube'deki lejyon komutanlığının ardından Arrianus Baetica Baetica Eyaleti'nde proconsul olarak görev almıştır. Corduba'da bulunan ve yazara ait olduğu düşünülen Artemis'e ithaf edilmiş bir şiir bulunmuştur. ${ }^{27}$ Şiirin sonunda

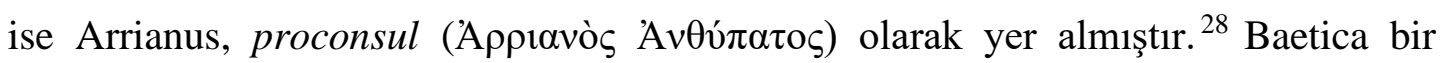
senatus eyaletidir ve praetorluk gibi merkezi bir konumdan bir senatus eyaletinde valiliğe geçiş, Arrianus'un bu noktada -ve kısa bir süreliğine- prestij kaybına uğradığını göstermektedir. Ayrıca, Baetica ve Arrianus'un daha sonra proconsul'lük yapacağı Cappadocia arasında bürokratik bir bağ olduğu da düşünülmektedir. M. Ulpius Traianus MS 67 yllından önce Baetica proconsulüyken, MS 70/71 - 72/3

\footnotetext{
${ }^{23}$ Syme, 185.

${ }^{24}$ Henry Francis Pelham, "Arrian as Legate of Cappadocia", The English Historical Review, 11/44 (1896): 628-629.

${ }^{25}$ Bir aileden Roma senatosuna giren ilk kişi.

${ }^{26}$ Arrianus'un Anabasis'te Danube hakkında verdiği detaylı bilgilerin kaynağında bu coğrafyaya hakim olması olabilir. Yazar buradaki halkları sıralarken Aleksandros'un dönemindekileri değil, kendi zamanının toplumsal yapısını ortaya koymuştur. Quadi ve Marcomanni gibi henüz Iulius Caesar döneminde belirgin hâle gelmiş olan toplulukların isimlerinin geçmesi bunu göstermektedir. Arr.Anab. 1.3.2; 5.4.1.

${ }^{27}$ Stadter, 10.

${ }^{28}$ Walter Burkert, "Nochmals das Arrian-Epigramm von Cordoba”, ZPE 17 (1973): 167 - 169.
} 
yıllarında Cappadokia'yı yönetmiştir; yine L. Antistius Rusticus MS 82 - 87 yılları arasında Baetica proconsullüğü yapmış, ardından MS 91/92 - 93/94 yıllarında Cappadocia'da görev almıştır. ${ }^{29}$ Yine C. Bruttius Praesens, MS 95/97 yıllarında Baetica'da quaestor olarak görev yapmış ve MS 121/122 - 123/124 yıllarında Cappadocia proconsüllüğünde bulunmuştur. ${ }^{30}$

Consül'lük görevi sırasında Augustus döneminde (MÖ 27-MS 14) oluşturulmuş curator aedium sacrarum et operum locorumque publicorum (kutsal yapılar ve kamu işleri sorumlusu) makamında görev yapmıştır. Bu göreve yalnızca consül getirilebiliyordu ve görev süresi bir yıldı. Daha önce de Cappadocia'da görev yapmış ve bu göreve getirilmiş dört kişi tespit edilmiştir. Bunlar M. Hirrius Fronto Neratius Pansa, P. Calvisius Ruso Iulius Frontinus, C. Bruttius Praesens ve L. Burbuleius Optatus Ligurianus'tur. ${ }^{31}$ Arrianus da bu görevde MS 130/131'de consüllüğü bittiği sırada bulunmuştur.

Yazar bir yıl Roma'da bu görevi yürüttükten sonra MS 131 y1lında Cappadocia Eyaleti'ne vali olarak atanmıştır. ${ }^{32}$ Yaklaşık 7 yıl süren bu görevi, Arrianus'un en hareketli ve aynı zamanda hararetli zamanlarıdır. Bölgeye atandığında Roma'nın burada bazı sorunlar yaşadığı bilinmektedir. Bunlardan ilki Armenia sınırında yaşananlardır. Roma'nın vasalları İberia ve Albania arasındaki çatışmalar bu bölgede bir istikrarsızlık teşkil ediyordu. Ayrıca Kazakistan steplerinden batı ve güneybatıya istila hareketleri düzenleyen Alanlar da ayrica tehlike yaratıyordu. Doğu sınırlarındaki bu sorunlar, barışın henüz tesis edildiği Parthların eline koz veriyor ve Armenia toprakları tehdit altında kalıyordu. ${ }^{33}$

Arrianus bu şartlar altında göreve başlamıştı ve proconsüllüğ̈̈u süresince de uğraşacağı meseleler bunlardı. MS 134'te Alanlarla olan mücadelesi sırasında onu Legio XV Apollinaris ile Melitene'deki (Malatya) Legio XII Fulminata'nın komutanı

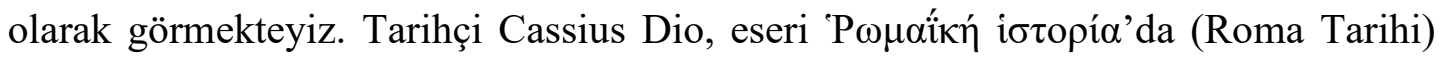

\footnotetext{
${ }^{29}$ Pelham, 625

${ }^{30}$ Wheeler, $44-45$.

${ }^{31}$ Wheeler, 51- 52.

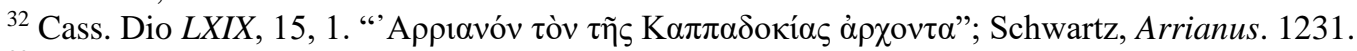

${ }^{33}$ FgrHist II B 156 T 2, 5; Phot. Bib. 58. 17a 25; Sarıkaya, 331.
} 
Cappadocia valisi Arrianus'a duyulan korkudan dolayı Alanların geri çekildiğini söylemektedir. ${ }^{34}$

Arrianus 50 yaşında ve imparatorluktaki kariyerinin zirvesinde Cappadocia'dan ayrılmıştır. Tarihçiler bundan sonra ne yaptığg sorusuna net bir yanıt verememiştir. Bir kesim, Hadrianus'un ya da varislerinden birinin Arrianus'un Cappadocia'daki yönetiminden memnun olmadığını ve bu görevi bırakmasının ardından kariyerinin de sona erdiğini öne sürmektedir. ${ }^{35}$ Bir başka kesim ise Arrianus'un kariyerinin tam tersine olumlu yönde ilerlediği ve Cappadocia'daki görevinin ardından Syria proconcül'lüğü yaptığını düşünmektedir. Yazarın çağdaşı Lucianos'un MS 135-150 yılları arasında Suriye valisi olan birinin felsefeye meraklı olduğunu söylemesi böyle bir iddianın ortaya çıkmasına sebep olmuştur. ${ }^{36}$ Fakat bu kesinlikten oldukça uzaktır.

MS 145-146 yılında, Hadrianus’un MS 131-132 tarihinde kurduğu Panhellenion'un (Hellen Birliği) merkezi Atina'nın onursal vatandaşı olmuş ve burada arkhonluk görevini üstlenmiştir. ${ }^{37} \mathrm{Bu}$ söz konusu dönemin önemli makamlarından biridir çünkü Panhellenion, kültürel olduğu kadar politik ve ekonomik bir örgütlenmedir. Asia ve Hellas'ın pek çok kenti de bu birliğe dahildir. ${ }^{38}$ Ayrıca yine Atina'da, boule ve ekklesia "ya başkanlık eden ve ayrıca MS 165- 175 yılları arasında dört dönem boyunca ekonomik sorumlulukları da olan prytanis görevinde bulunmuştur. ${ }^{39}$

Atina'daki hizmetlerinden dolayı kentte bir heykeli dikilerek onurlandırılmış, kaidesine de "L. Flavius Arrianus, consul rütbesine haiz filozof" yazılmıştır. ${ }^{40} \mathrm{Bu}$ bazı araştırmacıları Arrianus'un bir süre Atina'da kaldığına dair yorum yapmaya yönlendirmiştir. Bulunan yazıt Arrianus'un Atina'da bulunduğunu gösterse de burada ne yaptığına ya da ne kadar kaldığına dair bilgi vermez. Bu süreçten sonra bilinen en kesin şey Marcus Aurelius'un (MS 161 - 180) tahta

\footnotetext{
${ }^{34}$ Cass. Dio LXIX, 15.

${ }^{35}$ Schwartz, RE II, 1230 - 1231.

${ }^{36}$ Gustave A.Harrer, “Was Arrian Governor of Syria?”, Classical Philology 11/3 (1916): 338-339.

${ }^{37}$ James H. Oliver., “Arrian in Two Roles”, Hesperia Supplements 19 (1982): 127.

${ }^{38}$ Panagiotis N. Doukellis, "Hadrian's Panhellenion: A Network of Cities?", Mediterranean

Historical Review 22:2 (2007): 295 vd.

${ }^{39}$ IG III 1021, 1032; Sarıkaya, 331.

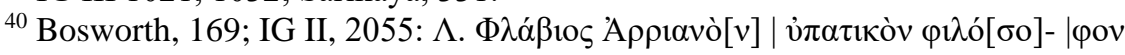


çıkmasıyla birlikte yazarın memleketi Nikomedeia'ya dönmüş olmasıdır ve muhtemelen MS 180 yılında da ölmüştür. ${ }^{41}$

\section{Arrianus'un Eserleri}

Arrianus'un politik kariyeri ile yazarlığı eş zamanlı olarak ilerlemiştir. Felsefe, tarih, coğrafya ve savaş ve askeri taktikler üzerine yazmış olduğu eserler, hareketli yaşamının izlerini yansıtırken, yaşadığı dönemin politik, ekonomik ve toplumsal yönleri hakkında da önemli anlatılar içermektedir. Bu çalışmada Arrianus'un eserlerinden kronolojik olarak söz etmeye çalışacağız.

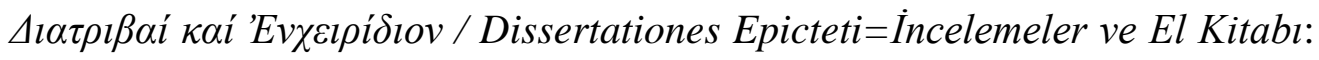
Epiktetos'un MS 124 yılında yayınlanan ilk eseri Diatribai Epiktetos'un söylevlerini ve onun yanında eğitim aldığı süre içindeki anılarını içermektedir. Enkheiridion adlı eseri ise Epiktetos'un felsefesi üzerine yazılmış bir el kitabıdır. Yazar, Korinthos'taki Lucius Gellius'a Epiktetos hakkında yazdıklarını bir mektupla iletmiştir. Mektubunda ise bu notların yayınlamak için değil, kişisel kullanım amacıyla kaleme aldığını belirtmiştir. Fakat bu metinler bir Arrianus'un rızası olmaksızın yayınlanmıştır. Hatta Arrianus, Epiktetos'un söylediklerini edebi bir yaklaşım izlemeden kaydettiği ve eserin üslubundan dolayı özür dileme ihtiyacı hissetmiştir. ${ }^{42}$ $\mathrm{Bu}$ eserin Arrianus'un bilgisi dışında yayınlandığını düşünmek için bir başka neden ise yazarın Indica eseri dışındaki diğer tüm eserlerinin Attik diyalekt ile yazılmış olmasına rağmen, bu eserin Koine diyalektinde yazılmış olmasıdır. ${ }^{43}$ Bunun yanında, Arrianus'un eserin yayınlanmasını bizzat sağladığını fakat isteği dışında yayınlanmış gibi göstermek için Lucius Gellius'a bu mektubu gönderdiği de iddia edilmektedir. ${ }^{44}$

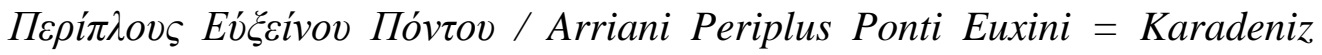
Seyahati: Arrianus'un MS 131/132 yılında kaleme aldığı bu eser, İmparator Hadrianus'u bölge hakkında bilgilendirmek için yazılmıştır. Eser üç ana bölümden oluşmaktadır ve bir kısmı Hadrianus'a mektup biçimindedir. Birinci bölümde Trapezos (Trabzon) ile Dioskourias/Sebastopolis (Sohum) arası, ikinci bölümde

\footnotetext{
${ }^{41}$ Bosworth, 181; Günay Karahan., "Nikomedialı Arrianus Üzerine Bir Değerlendirme", Sosyal Bilimler Araștırma Dergisi (KOUSBAD) 6 (2017): 4.

${ }^{42}$ Wheeler, 396 - 397.

${ }^{43}$ Schwarts, RE II, 1231 - 1232;

${ }^{44}$ Bosworth, 169.
} 
Byzantion'dan (İstanbul) Trapezos'a kadar sahil şeridi, üçüncü bölümde ise Kuzeydoğu Karadeniz'in Roma hakimiyetinin uç noktasında olan Dioskourias'tan Byzantion'a kadar sahil şeridi tasvir edilmiştir. Karadeniz'deki kaleler, limanlar, oradaki gelenekler ve hava durumu hakkında detaylı bilgiler vardır. Arrianus şehirleri ve yapıları betimlemiştir. Coğrafi bilgiler verdiği bu eserde Ksenophon'un da bölgede seyahat ettiğini söylemektedir. Ayrıca Hadrianus anıtı, yazar tarafından tasvir edilmiştir. ${ }^{45}$

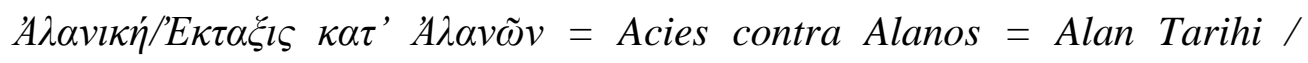
Alan'lara Karşı Savaş Düzeni: Arrianus, bu eserinde MS 135 yılına Cappadocia valisiyken yukarıda da sözünü ettiğimiz Alan'lara karşı yaptığı savaşı konu almıştır. Yarı edebi bir çalışma olan bu eserinde yazar, komuta ettiği legio'nun ilerlemesini ve bu legio'nun oluşumunu tasvir etmiştir. ${ }^{46}$ Fragmanlar halinde günümüze kadar korunan bu eseri Arrianus, İmparator Hadrianus'a ithaf etmiştir. ${ }^{47} \mathrm{Bu}$ eser Roma ordu ve ordu sistemi hakkında detaylı bilgiler içermektedir.

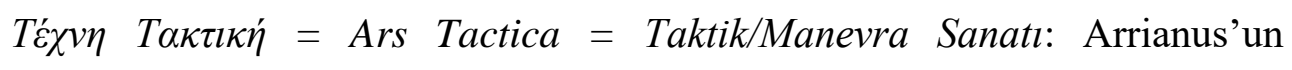
Cappadocia'daki görev yaptığı dönemde yazdığı üçüncü eseridir. Alanlarla olan savaştan eyalet başkenti Caesarea'ya döndükten bir yıl sonra, Hadrianus'un hükümdarlığının 20. Yılında, yani MS 136 yılında kaleme almıştır. ${ }^{48}$ Bu nedenle Alanlarla yapılan savaştaki deneyimleri hâlâ aklındadır. Bunun yanında, öncüleri Asklepiodotos ve Aelianus'un askeri inceleme geleneğine de hâkim olmalıdır. ${ }^{49}$

Kitap temel olarak iki bölüme ayrılmaktadır. İlk bölüm Hellenistik falanksın organizasyon, tatbikat ve düzenini içermektedir. İkinci bölüm ise süvari eğitimi ve organizasyonu ile ilgilidir. $\mathrm{Bu}$ iki ana bölümün altında ise sekiz alt bölüm bulunmaktadır. Hadrianus dönemi Roma ordusunun savaş taktikleri, ordunun kıyafetleri detaylı bir şekilde betimlenmiştir. ${ }^{50}$

\footnotetext{
${ }^{45}$ Arthur.G. Ross, "Ad Ursulum Philippum Boissevain Septuagenarium Epistula de Arriani Periplo Ponti Euxini”, Mnemosyne LIV (1926), 101 - 107.

46 Pelham, 130.

${ }^{47}$ Arr. Tact. 44, 3; Philip A. Stadter, "The Ars Tactica of Arrian: Tradition and Originality", Classical Philology 73 (1978) 119.

${ }^{48}$ Arr. Tact. 44, 3.

${ }^{49}$ Arr. Tact. 1.2.

${ }^{50}$ Wheeler, 329.
} 


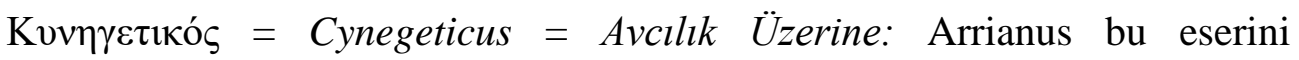
Cappadocia valiliğinden sonra, muhtemelen Atina'da bulunduğu süreçte MS 145/146 yılında kaleme almıştır. Kahramanı Ksenophon'un Kynegetikos eserinden esinlenerek yazmıştır. Ksenophon'un meşhur yapıtına ek niteliğindeki son derece mütevazi bir çalışmadır. Arrianus bu çalışmasında kendisini Ksenephon'un kentinin yurttaşı olarak tanımlamıştır. ${ }^{51}$ Eserde avcılık hayatıyla, aile ilişkileri ve günlük yaşamıyla ilgili pek çok bilgi bulunmaktadır. ${ }^{52}$

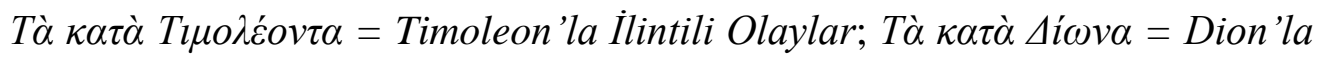
İlintili Olaylar: Sicilia'daki Syrakusai ile bütün Sicilia'yı tiranlıktan kurtaran Amiral Timoleon'un askeri kariyerini ve Syrakusai'lı Dion'u anlatan monografik bir çalışmadır. ${ }^{53}$

Av $\alpha \beta \alpha \dot{\alpha} \sigma \varepsilon \omega \varsigma$ A $A \lambda \varepsilon \xi \dot{\alpha} v \delta \rho o v \quad \beta \imath \beta \lambda i o v=$ Alexandri Anabasis = Iskender'in Anabasis ' $i$ : İmparator Hadrianus Dönemi'nde, Arrianus'un kaleme aldığı tarih eseri

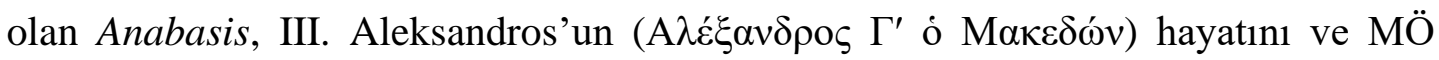
336-323 arasındaki Pers seferlerini anlatmaktadır. Ksenophon'un Anabasis'ine üslup ve yazı tarzı bakımından benzerlik gösteren bu eser yedi kitaptan oluşmaktadır. Arrianus'un yazarlık kariyerinin en önemli eseridir diyebiliriz. ${ }^{54}$

Eserin hangi tarihte yazıldığı hakkında iki görüş bulunmaktadır. Bunlardan biri Anabasis'in en erken MS 168 yılında yazıldığı yönündedir. Buna kanıt olarak da Arrianus'un, Lucianus'un MS 165 y1lında yayınlanan Quomodo historia conscribenda (Tarih Nasıl Yazılır?) eserindeki tarihsel hataları düzeltmesini göstermektedirler. ${ }^{55}$ Buna karşılık, Anabasis’te Cappadocia coğrafyası ile ilgili yapılan çok sayıda hatayı göstererek, bu eserin ancak Arrianus'un bu bölgedeki valiliğinden önce yazılmış olabileceğini iddia etmektedir ve MS 115 - 125 yılları arasını işaret etmektedir. ${ }^{56}$ Kitapta Cappadocia'ya ayrılan kısmın oldukça az olması ve Aleksandros'un güzergahının Arrianus'un eylem alanındak uzak olduğu

\footnotetext{
51 Arr.Kyn. 1.4.

52 Wheeler, Flavius Arrianus, 385-385.

${ }^{53}$ Sarıkaya, 33.

${ }^{54}$ Stadter, 180.

${ }^{55}$ Hans Nissen, "Die Abfassungzeit von Arrians Anabasis", RhM XLIII, (1888): 236 - 257.

${ }^{56}$ Friedrich Reuss, “Arrian und Appian”, RhM LIV (1899): 446 - 465.
} 
düşünülürse, yazarın eseri proconsül'lüğünden sonra yazdığını söylemek mümkündür.

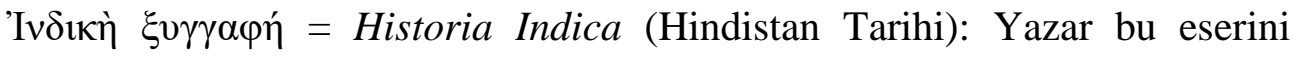
Atina'da kaleme almıştır. Ion lehçesinde yazdığı eserde Arrianus, Büyük III. Aleksandros'un Giritli komutan Nearkhos'un komutasında güney Hindistan'a, Pers Körfezi ve Susa'ya kadar gelişini aktarmıştır. ${ }^{57}$

Eserde Anabasis'e pek çok atıf bulunduğundan, eserin Anabasis’ten sonra yazıldığını söylemek mümkündür. Ayrıca Lucianus'un Quomodo Historia Conscribenda eserinde Hindistan'da ve bir dış deniz seferinde gerçekleşen olayları aktaracak bir tarihçiyle dalga geçmektedir. ${ }^{58} \mathrm{Bu}$ kanıtlardan yola çıkarak, eserin yazılış tarihi olarak en erken MS 165 yılı gösterilebilir.

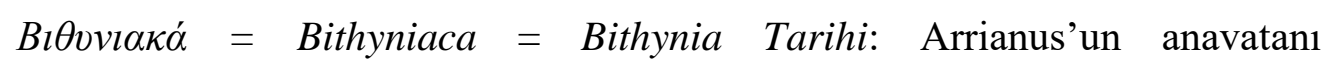
Bithynia'nın efsanevi ve önemli tarihi kişiliklerini anlattığı sekiz kitaplık eseridir. Bithyniaca, Arrianus'un dördüncü tarihi kitabıdır. Bithynia'nın mitolojik ve genel tarihini ayrıntılı bir şekilde anlatmıştır. Nikomedeia'da doğduğunu, orada yetiştirildiğini ve orada eğitim gördüğünü, Demeter ve kızının (Kore) kentin kutsal rahibeleri olduğunu bu metinde söylemektedir. ${ }^{59}$ Photios, Arrianus'un bu edebi uğraşında en başından beri Bithynia'nın tarihini ele almayı amaçladığını söylemiştir ancak malzeme eksikliğinden dolayı eserin tamamlanmasının biraz zaman aldığını ve bu nedenle geciktiğini yazmıştır. ${ }^{60}$ Arrianus'un Bithyniaca adlı eserinde, günümüze kalan fragmanlarında, Nikomedeia'nın Bithynia Bölgesi'nin emporion'u olduğunu söylemektedir. ${ }^{61}$ Arrianus'tan kalan fragmanlarda, vaktiyle Bithynia'liların donanmalarının olduğunu ve onların ülkesinin hep üretken, güzel ağaçlarla örtülü olduğunu, birçok yerde taş oymacılığı yapıldığını öğrenmekteyiz. ${ }^{62}$

П $\alpha \rho \theta \kappa \alpha \dot{~}=$ Parthica $=$ Parth Tarihi: İmparator Traianus'un (MS 98-117) hükümdarlığı sırasında Parthia ile Roma arasındaki savaşları anlatan 17 kitaptan

\footnotetext{
${ }^{57}$ F. F. Schwarz, “Arrian's Indike on India: Intention and Reality”, East and West 25 (1975): 181-200.

${ }^{58}$ Lucianus, 31.

${ }^{59}$ Arthur G. Roos, Flavii Arriani Quae Exstant Omnia, vol II, Leipzig 1968, 197.

${ }^{60}$ Arthur G. Roos, 197.

${ }^{61}$ Arthur G. Roos, 199.

${ }^{62}$ Arthur G. Roos, 203.
} 
oluşan eseridir. Yazar, bu eseri Traianus'un Parthlarla savaşının bitmesinden sonraki bir dönemde, MS 114-117 kaleme almıştır. ${ }^{63}$ Arrianus, eserinde Parthların kökeninin zamanla nasıl güçlendiklerini anlatmış ve daha sonra da Traianus ile Parthlar arasındaki savaşı yazmıştır. Eserin büyük bir kısmı kayıptır, yalnızca fragmanlar bulunmaktadır. Bu Arrianus'un en uzun eseridir aynı zamanda.

Eserin birinci kitabında Arrianus Parthların kökenleri ve imparatorluğun doğuşu hakkında bilgi vermektedir. İkinci, üçüncü ve dördüncü kitaplarda Cassius'un Parth seferini, II. Triumvirlik zamanındaki gelişmeleri ve Marcus Antonius'un Parthlarla olan mücadelesini kronolojik olarak aktarmaktadır. Beşinci, altıncı ve yedinci ciltler ise Flaviuslar döneminde Parthlarla olan ilişkiler yer almaktadır. Kalan on kitap ise Traianus'un Parth seferinin detaylı incelemesini içermektedir. ${ }^{64}$

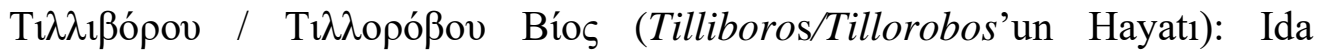
Dağı'nda veya Mysia'da yaşayan Haydut Tilliboros'un hayatını ele aldığı biyografi türünde bir eserdir. Tilloboros'un yaşadığı yer Nikomedeia'dan çok uzak değildir. Eser günümüze kadar gelmemiştir. ${ }^{65}$

$\tau \grave{\alpha} \mu \varepsilon \tau \grave{\alpha}$ 'A $\lambda \varepsilon \xi \xi_{\alpha} \delta \delta \rho o v=$ Historia Suscessorum Alexandri $=$ İskender'den Sonra: Arrianus İskender'in ölümünün ardından, imparatorluğun bölünmesi sonrasında Diodokhoi'un kurduğu krallıklar hakkında on kitaplık bir eser yazmıştır. $\mathrm{Bu}$ eserde yazar, imparatorluğun yazgısını ve komutanların taht kavgalarını konu almıştır. Eserin tarihi konusunda iki farklı görüş bulunmaktadır. Bunlardan ilki eserin Anabasis’ten önce yazıldığını öne sürmektedir ${ }^{66}$

Arrianus, Geç Antik Dönem'de methedilen bir düşünür olmuştur. Yazar, aynı zamanda komutan ve devlet adamı olarak görev yapmıştır. Arrianus, Hellen kültürüyle yetişmiş ve eserlerini Hellen dilinde yazmış bir Roma vatandaşıdır. Bithynia-Nikomedeia'lı düşünür, asker ve devlet adamı ve aynı zamanda övülmeye değer bir tarihçidir.

\footnotetext{
${ }^{63}$ Syme, 182, 205; Bosworth, 181.

${ }^{64}$ Wheeler, $409-410$.

${ }^{65}$ Sarıkaya, 334 - 335.

${ }^{66}$ Gerhard Wirth, “Arrianos”, Der Kleine Pauly, c.I, Stuttgart 1964, 606 - 607.
} 


\section{Cassius Dio Cocceianus'un Yaşamı ve Eseri}

Bithynia bölgesinin önemli kentlerinden Nikaia'da doğan Dio/Dion Cassius olarak da bilinen Cassius Dio Cocceianus, yak. MS 150-235 yılları arasında yaşamış ${ }^{67}$, Roma İmparatorluk Dönemi’nin önemli tarih yazarlarındandır. Cassius Dio'nun babası, Romalı bir senatör ve aynı zamanda Cilicia ve Dalmatia'da valilik (legatus) yapmış olan Cassius Apronianus'tur. ${ }^{68}$ Dedesi ise ünlü hatip ve filozof Dio Chrysostomos'dur. ${ }^{69}$ Dio Cocceianus Chrysostomos yak. MS 40-115 yılları arasında yaşamış, Bithynia-Prusa doğumlu, varlıklı, iyi bir eğitim almış hatip ve filozoftur. Cassius Dio'nun annesi Dio Chrysostomos'un kızıdır. ${ }^{70}$

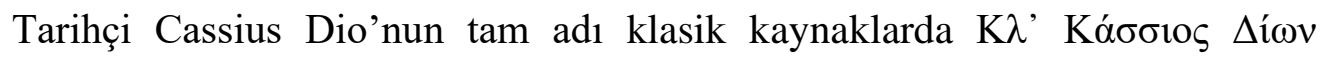
olarak geçmektedir. ${ }^{71}$ MS 3.-7. yüzyıllar arasına ait olan belgelere göre Cassius Dio'nun adı Claudius Cassius Dio olarak geçmektedir. ${ }^{72}$

Cassius Dio, Roma İmparatorluğu'na bağlı ve devlete hizmet etmeyi onur kabul eden saygın bir aileden gelmektedir. Babasının Cilicia valisi olarak görev yaptığı dönemde, onunla yaşadığını biliyoruz. ${ }^{73}$ Yazar, babası tarafından eğitim alması için Asia Eyaleti'ne gönderilmiştir. İyi bir eğitim alan Cassius Dio, büyük bir ihtimalle cursus honorum'u tamamlamıştır. ${ }^{74}$ Babasının ölümünden sonra MS 180 y1lı civarında Roma’ya gitmiştir. ${ }^{75}$

Cassius Dio'nun ilk kamu tribunus militum laticlavius'tur. ${ }^{76}$ Yazar, Marcus Aurelius’un hükümdarlığının ilk yıllarında doğup, yetişmiştir. İmparator P. Helvius Pertinax, (MS 193) Cassius Dio’yu 193 yılında, bir sonraki yıl için praetor'luk makamına aday göstermiştir. ${ }^{77}$ Ancak P. Helvius Pertinax ve halefi M. Didius

\footnotetext{
67 Yazarın doğum tarihi senatus'a giriş tarihi esas tutulduğu zaman MS 155-164 yılları arasına yerleştirilebilir.

${ }^{68}$ Dio Cass. LXIX, 1, 3; LXXII, 7, 2;

${ }^{69}$ E. Cary, Dio's Roman History I, London-New York 1964, VII.

${ }^{70}$ Cassius Dio'nun babası M. Cassius Apronianus'un hatip Dio Chrysostomos ile herhangi bir ortak ismi paylaşmıyor olması ilgi çekicidir. Yazarın anne tarafının ismini almış olduğu görünmektedir. Annesi Claudia soyuna mensup, Cassius Apronianus ile evlenmiş olduğunu varsayabiliriz.

${ }^{71}$ Alain M. Gowing, “Dio’s Name”, Classical Philology 85/1, (1990): 49.

72 Alain M. Gowing, 54.

73 Dio Cass. LXXII, 7. 2.

${ }^{74}$ Soylu bir Roma vatandaşının, memuriyet görevlerinde ilerleme kaydetme aşamaları.

${ }^{75}$ Cary, VII.

${ }^{76}$ Askeri tribunus: H. M. D Parker, The Roman Legions, Harvard 1928, 188-189.

${ }^{77}$ Dio Cass. LXXIII, 12, 2.
} 
Iulianus iktidardan devrildiği için, Cassius Dio, İmparator Septimius Severus Dönemi’nde (MS 193-211) praetor olmuştur. ${ }^{78}$ MS 193 yıl1, aynı zamanda Cassius Dio'nun edebi çalışmalarına başladığı yıl olmuştur. Cassius Dio ilk olarak İmparator Septimus Severus'u öven, rüya ve kehanetleri içeren küçük bir kitap kaleme almıştır. ${ }^{79}$ Rüyalara ve kehanetlere çok itibar eden tarihçi Cassius Dio, Septimius Severus'a zafer getiren bu sonucu (Byzantion kentinin teslim olması) bir rahibin gördüğü rüya ile ilişkilendirmiştir. ${ }^{80}$ Ayrıca MS 193-197 yılları arasındaki iç savaşları konu alan bir tarih yazmıştır. ${ }^{81}$

Yazar, rüyalar ve kehanetler hakkında yazdı̆̆ı eserini İmparator'a göndermiştir ve O’ndan ayrıntılı ve övgü dolu bir yanıt almıştır. Mektubu okuduktan sonra Cassius Dio, rüyasında tanrı tarafından tarih yazmakla görevlendirildiğini

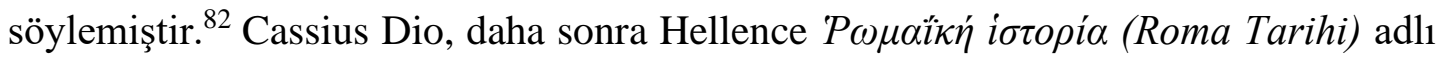
eserini yazmaya karar vermiştir. ${ }^{83}$ Yazar, daha önce yazmış olduğu küçük eserini de bu kitabın içerisine yerleştirmiştir. ${ }^{84}$ Roma Tarihi adlı eserini büyük ölçüde Capua' da yazmıştır. 80 kitaptan oluşan eser, başlangıçtan MS 229 yılına kadar olan, yaklaşık bin yıllık zamanı kapsar. Cassius Dio'nun eserinden öğrendiğimize göre, Roma Tarihi'ni yazmak için on yıl materyal toplamıştır, yazıya geçirmek için de 12 yıl harcamıştır. ${ }^{85}$ Tarihlendirmek gerekirse Cassius Dio (MS 201-211) yılları arasında malzeme toplamış, MS 212-224 yılları arasında da Roma Tarihi adlı eserini yazmıştır, yani İmparator Septimius Severus'un (MS 193-211) yönetiminde, eser için malzeme toplanmış, İmparator Severus Alexander'in (MS 222-235) yönetiminin başında ise eserin yazımı bitmiştir. $^{86}$

\footnotetext{
${ }^{78}$ Cary, VIII.

79 Dio Cass. LXXII, 23, 1; M. J. Höfner, "Die zeitengenössische Geschichte des Cassius Dio", Rheinisches Museum für Philologue, vol. 27, Frankfurt am Main 1872, s. 157; Mehmet Ali Kaya., Roma 'nın Afrikalı Imparatoru Septimius Severus, İstanbul 2008, 157, dn. 420.

${ }^{80}$ Kaya, 171.

${ }^{81}$ M.C. Howatson, Oxford Antikçağ Sözlüğü, çev. F. Ersöz, İstanbul 2013, 170.

${ }^{82}$ H.J. Hillen, Cassius Dio Römische Geschichte, c.I, Berlin 2012, 14.

${ }^{83}$ Dio Cass. LXXII, 23, 1-2.

${ }^{84}$ Dio Cass. $L X X I V, 3.3$.

${ }^{85}$ Dio Cass. LXXII, 23, 5.

86 Timothy D. Barnes, "The Composition of Cassius Dio's "Roman History"” Phoenix 38/3 (1984): 241.

* Görev süresi içinde bir boşluğu doldurmak üzere atanmış kişi. Consul'ün yerine atanan kişi.
} 
Cassius Dio, Septimius Severus zamanında concul suffectus* olmuştur, ancak göreve başladığı yıl kesin olarak bilinmemektedir. Septimius Severus’tan sonra imparator olan Caracalla Dönemi'nde (MS 198-217) ise Cassius Dio imparator ile Bithynia'ya gelmiş ve kışı Nikomedeia'da geçirmiştir. (MS 214-215). ${ }^{87}$ Daha sonra MS 217 yılında İmparator Macrinus MS 217-218 tarafından Pergamon ve Smyrna'ya curator olarak atanan Cassius Dio, imparator Elagabalus döneminde de (MS 218-222) bu görevi sürdürmüştür. ${ }^{88}$ MS 218-219 kışında Pergamon'da kalan yazar, oradan Bithynia'ya gitmiş ve orada hastalanmıştır. ${ }^{89}$ Severus Alexander kendisini çağırıncaya kadar Bithynia'da kalmıştır.

İmparator Severus Alexander (MS 222-235), Cassius Dio'yu Africa Eyaleti'ne praetor olarak görevlendirmiştir (MS 223-224). ${ }^{90}$ Atama haberini Bithynia'dayken alan yazar, oradan hemen atandiğ 1 yere gitmiştir. Bu görevden sonra legatus Augusti olarak MS 224-226 yıllarında Dalmatia'ya, daha sonra da MS 226-228 yıllarında Pannonia Superior'a (yukarı Pannonia) gönderilmiştir. ${ }^{91}$ İmparator Severus Alexander, Cassius Dio'yu MS 229 yılı için ikinci kez consul olarak atamıştır. ${ }^{92}$ Consul'lüğü sırasında yaşından ve ayak ağrılarından dolayı, Bithynia'ya dönmek için imparatordan izin almış ve evine, doğduğu topraklara dönmüştür. ${ }^{93}$ Yazar, kısa bir süre sonra da hayatını kaybetmiştir.

Cassius Dio'nun yayımlamış olduğu 80 kitaptan oluşan, Hellence yazılmış

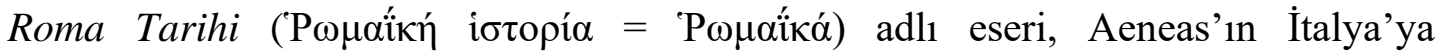
gelmesinden MS 229 yılına kadar olan dönemi kapsamaktadır. Yazar, yaklaşık bin yıllık bir süreyi ele almaktadır.

Cassius Dio, Hellen edebiyatı ve rhetoriği hakkında iyi bir eğitimden geçmiştir. Yazar, Roma tarihini ve politik yaşamını Hellence ifade etmiştir. Cassius Dio'nun yetiştiği atmosferi, yükselen bir Hellen bilinci ile karakterize etmek mümkündür. Bununla birlikte, Hellen eğitimi ve kültürüyle yetişmiş bir kişi olmasına

\footnotetext{
${ }^{87}$ Dio Cass. LXXVII, 18, 1; Fergus Millar, A Study of Cassius Dio, Oxford 1964, 19.

${ }^{88}$ Curator. Devlet gücünü kullanmak üzere görevlendirilen yönetici. Dio Cass. LXXIX, 7.4.

${ }^{89}$ Dio Cass. $L X X X, 1,2$.

${ }^{90}$ Dio Cass. $L X X X, 1,2 ;$ Barnes, 244.

${ }^{91}$ Dio Cass. $L X X X, 1,3$.

${ }^{92}$ Dio Cass. $L X X X, 5$, 1; Eduard Schwartz, "Cassius", RE III, Stuttgart 1899, 1684.

${ }^{93}$ Dio Cass. LXXX, 5, 2; J, D. Harrington., "Cassius Dio as a Military Historian", Acta Classica 20 (1977): 160.
} 
rağmen düşüncesi, tutumu ve bakış açısı ile Romalıdır, ayrıca bizzat bir senatör olarak imparatora ve rejime bağlıdır. Roma Tarihi adlı eserinde de olayları bir Romalı gözüyle değerlendirmiştir. Özellikle imparatorluk döneminin başlangıcıyla ilgili verdiğgi bilgiler, Roma tarihçiliğgi açısından eserin önemli bir nitelik kazanmasını sağlamıştır. Eser, aynı şekilde Cumhuriyet, İmparatorluğun kuruluşu ve yükselişi aşamalarıyla ilgili, zaman zaman kuşkulu veriler içermesine rağmen önemli bir bilgi kaynağıdır. Devleti yüceltmek amacıyla yazdığı bu eser, bugün modern tarihçilerin sık sık başvurduğu kapsamlı bir kaynaktır. Kendi zamanının olaylarını anlatırken Dio, siyasi kariyeri boyunca olduğundan daha fazla özgürlüğe sahiptir ve bu özgürlüğü de yaşadığı dönemin gerçek muhasebesini yapmak için kullanmaya özen göstermiştir. ${ }^{94}$

Cassius Dio, yaşadığı dönemin olaylarının önemli bir tanığıdır. Kendisinin devlet adamı olması ve kişisel deneyimi dolayısıyla ve devlet kayıtlarını kullanmaya özen gösterdiği için siyasal tarih açısından değerli yorumlar yapmıştır. Ed. Schwartz, Cassius Dio'nun “dik başll, sağlam karakterli bir Bithynia'll” olduğunu ifade etmiş ve yazarı "Bithynia'nın dürüst ve liyakatli bir kişiliğĭ" olarak tanımlamıştır. ${ }^{95}$

Cassius Dio'dan önceki dönemde yaşamış en önemli Bithynialı hatip, sofist ve tarihçi Nikomedeia'lı Arrianus'tur. Cassius Dio, İmparator Traianus'un Parth savaşını betimlerken büyük ölçüde Arrianus'un Parthica adlı eserinden yararlanmıştır. ${ }^{96}$ Bunun yanında Dio, eserinde rhetoriği ustaca kullanmış ve özellikle uzun konuşmalara yer vermiştir. Ayrıca yazar olayları dramatize ederek anlatmakta ustadır. Bu bağlamda Arrianus'tan ayrılmaktadır. ${ }^{97}$

\section{Sonuç Yerine}

Bithynialı Lucius Flavius Arrianus ve Claudius Cassius Dio Cocceianus, Roma İmparatorluğu'nda consul olarak görev yapmış yazarlardır. İkisi de eserlerini kaleme almadan önce, benzer şekilde özenli bir hazırlık süreci geçirmiştir. Arrianus

\footnotetext{
${ }^{94}$ Andrew Scott, "Cassius Dio's Contemporary History as Memoir and Its Implications for Authorial Identity", Paper of the Langford Latin Seminar 17 (2017): 19.

${ }^{95}$ Schwartz, Cassius, 1689.

${ }^{96}$ Karl Hartmann," "Ueber das Verhältnis des Cassius Dio zur Parthergeschichte des Flavius Arrianus", Philologus 74, 1917,73; Walter Ameling, "Cassius Dio und Bithynien", Epigraphica Anatolica 4 (1984): 129.

${ }^{97}$ Albin Lesky, A History of Greek Literature, New York 1966, 850.
} 
dönemin en önemli filozoflarından Epiktetos'un yanında eğitim almıştır. Düşünce yapısı da henüz ilk gençliğinde burada şekillenmiş, Hadrianus ile bu süreçte tanışmış ve sonrasında imparatorluktaki kariyerinde hızlı bir tırmanış yaşamıştır. Cassius Dio da iyi bir eğitim alması için Asia Eyaleti'ne gönderilmiş ve bu eğitimden geçtikten sonra çeşitli kamu görevlerinde yer alarak consüllüğe kadar ulaşmıştır.

Özellikle Arrianus hem Stoacı eğilimi hem de Hellen kültürüne, politik ve askeri yapısına olan yakınlığı nedeniyle Antoninuslar Dönemi'nin İkinci Sofistik dünyasının bir sembolü hâline gelmiştir. Hellen kökenli bir yurttaş olarak kritik görevler almış, ordu komutanlığı ve consüllük yapmıştır ki bu da Hadrianus döneminin Panhellenik esintisine oldukça uygundur. Ayrıca emeklilik yıllarını, Hadrianus'un, kendi tanrısallığı çevresinde örgütlediği Panhellenion'un (Hellen Birliği) merkezi Atina'da geçirmiş ve burada Panhellenion'un arkhonluk ve prytanlık makamlarında bulunmuştur.

Arrianus ve Cassius Dio Roma tarihi ile ilgili çalışmalar kaleme alarak Hellenler üzerindeki Roma egemenliğini hakl1 göstermiş görünmektedir ve böylece Roma'nın Hellen coğrafyası üzerindeki egemenliğini pekiştirmeye çalışmışlardır. Hatta Arrianus bizzat imparator için taktik el kitapları ve coğrafya eserleri hazırlamıştır. Diğer taraftan, bu iki önemli figür eserlerini Hellen dilinde kaleme almıştır. Dile olan hakimiyetleri ve edebi üslupları aldıkları eğitimin bir ürünüdür ki bu da Hellenistik bir eğitimdir. Hellen kültürünün imparatorluk tarihindeki en parlak döneminin birer ürünüdür. Bu nedenle, yazdıklarıyla ya da yaşam tarzlarıyla Roma egemenliğini pekiştirmeye çalışırken, Roma'nın Hellen kimliğini koruduğu ve özellikle doğudaki topraklarının politik ve kültürel birliği için onu bir araç olarak kullandığını da göz önünde bulundurmak gerekmektedir.

\section{Kaynakça}

Ameling, Walter., “Cassius Dio und Bithynien”, Epigraphica Anatolica IV (1984): 123-138. Ameling, Walter, "L. Flavius Arrianus Neos Xenophon", Epigraphica Anatolica IX (1984): 119-122. Arrianus, "Tactica. Tactica", Flavii Arriani quae extant omnia, ed. A. G. Roos and G. Wirth vol. 2, Leipzig 1968, 129-176.

Arslan, Murat, Arriani Periplus Ponti Euxini=Arrianus'un Karadeniz Seyahati, Çev.: M. Arslan, İstanbul: 2005.

Barnes, Timothy David., “The Composition of Cassius Dio's "Roman History”, Phoenix, 38/3 (1984): 240-255. 
Boissevain, Ursul Philip, Cassi Dionis Cocceiani Historiarum Romanarum Quae Supersunt, vol. I-IIIII-IV, Berlin: 1955.

Bosworth, Albert Brian., “Arrian's Literary Development”, Classical Quarterly 22 (1972): 163-185.

Bowie, E.L., Greek and their Past in the Second Sophistic", Past \& Present 46 (1970): 3 - 41.

Boyana, Hülya, "Bithynia Bölgesinin Tarihi ve Kullandıkları Takvim", Uluslararası Gazi Süleyman Paşa ve Kocaeli Tarihi Sempozyumu III, Kocaeli 2017, 153 - 164.

Burkert, Walter "Nochmals das Arrian-Epigramm von Cordoba", ZPE 17 (1973): 167 - 169.

Corpus Inscriptionum Latinarum (CIG). ed.T. Mommsen, Berlin: 1853.

Cary, E., Dio's Roman History I, The Loeb Classical Library, London-New York: 1964.

Dio, Cassius, Roman History I, çev. E. Cary, London: 1964.

Dio Cassius, Cassii Dionis Cocceiani Historiarum Romanarum I-II-III-IV, ed. U. P. Boissevain,

Berlin: 1955.

Jacoby, F., Die Fragmente der griechischen Historiker. (FGr Hist), Berlin: 1923 ff.

Gowing, Alain M., "Dio's Name”, Classical Philology 85/1 (1990): 49-54.

Harrer, Gustave. A., "Was Arrian Governor of Syria?", Classical Philology 11/ 3 (1916): 338-339.

Harrington, J. D., "Cassius Dio as a Military Historian”, Acta Classica 20 (1977): 159-165.

Hartmann, K., "Ueber das Verhältnis des Cassius Dio zur Parthergeschichte des Flavius Arrianus", Philologus 74 (1917): 73-91.

Hillen, H. J., Cassius Dio Römische Geschichte, c. I, Berlin: 2012.

Hist. Aug. Vit. Hadr. Scriptores Historiae Augustae, Hadriani. The Scriptores Historiae Augustae. çev.D. Magie, The Loeb Classical Library, New York: 1968.

Howatson, Margaret. C.,Oxford Antikçağ Sözlüğü, çev. F. Ersöz, İstanbul: 2013.

Höfner, M. J., "Die Zeitgenössische Geschichte des Cassius Dio", Rheinisches Museum für

Philologue 27 (1872): 156-158.

IGR, Inscriptiones Graecae ad res Romanas Pertinentes.

Karahan, Günay, "Nikomedialı Arrianus Üzerine Bir Değerlendirme", Sosyal Bilimler Araştırma

Dergisi (KOUSBAD) 6 (2017): 1-14.

Kaya, Mehmet Ali, Roma'nın Afrikalı İmparatoru Septimius Severus, İstanbul: 2008.

Lesky, Albin, A History of Greek Literature, New York: 1966.

Lucianus, Alexander, çev. A. H. Harmon, c.4, New York: 1925.

Millar, Fergus, "Epictetus and Imperial Court", JRS 55 (1965): 141-148.

Millar, Fergus, A Study of Cassius Dio, Oxford 1964.

Nissen, Hans, "Die Abfassungzeit von Arrians Anabasis", Rheinisches Museum XLIII, (1988): 236 257.

Oliver, James H., “Arrian in Two Roles”, Hesperia Supplements 19 (1982): 122-129.

Panagiotis N. Doukellis, "Hadrian's Panhellenion: A Network of Cities?", Mediterranean Historical Review 22:2, 2007, 295 - 308.

Parker, H. M. D., The Roman Legions, New York: 1928.

Pelham, Henry Francis., "Arrian as Legate of Cappadocia", The English Historical Review, vol II,

No.44, UTC 1896, s. 625-640.

Photios, Bibliotheka., çev. R. Henry, Paris 1971.

Roos, Arthur G., Flavii Arriani Quae Exstant Omnia, vol. II, Leipzig 1968.

Ross, Arthur G., "Ad Ursulum Philippum Boissevain Septuagenarium Epistula de Arriani Periplo Ponti Euxini", Mnemosyne LIV (1926), 101 - 107.

Sarıkaya, Sevgi., "Arrianus'un “İskender'den Sonraki Olaylar" Adlı Eseri”, Cedrus I, Antalya 2013, 329-345.

Schwartz, Eduard, "Arrianus", Paulys Real-Encyclopädie der classischen Altertumswissenschaft, c.II.1., Stuttgart 1895, 1230-1247.

Schwartz, Eduard, "Cassius", Paulys Real-Encyclopädie der classischen Altertumswissenschaft, c.II.2., Stuttgart 1899, 1684-1722.

Schwartz, F. F., “Arrian's Indike on India: İntention and Reality”, East and West 25, 1975, 181-200.

Scott, Andrew, "Cassius Dio's Contemporary History as Memory and Its Implications for Authorial

Identity", Paper of the Langford Latin Seminar 17, 2017, 1-23.

Stadter, Philip. A., Arrian of Nicomedia, Chapel Hill: 1980.

Stadter, Philip. A., "The Ars Tactica of Arrian: Tradition and Originality", Classical Philology 73 (1978): 117-128.

Suidas, Suidae Lexicon., ed. A. Adler I-IV, Leipzig-Teubner: 1928-1971. 
ESOGÜ TARIH DERGISI

Cilt 4, Sayı:2, 2021, 18-36

Syme, Ronald, "The Career of Arrian", HSCP 86 (1982): 181-211.

Wheeler, Wverett Lynn, Flavius Arrianus: A Political and Military Biography, Doktora Tezi, Duke University Department of Classsical Studies, Durham: 1970.

Wirth, Gerhard, “Arrianos”, Der Kleine Pauly, c.I, Stuttgart:1964, 606 - 607.

Woloch, Michael, Raman Citizenship and the Athenian Elite, A.D.96 -161, Amsterdam: 1989. 